\title{
Ecological stoichiometric characteristics and influencing factors of carbon, nitrogen, and phosphorus in the leaves of Sophora alopecuroides L. in the Yili River Valley, Xinjiang
}

\author{
Yulu Zhang ${ }^{1,2}$, Dong Cui ${ }^{\text {Corresp., 1, 2, } 3}$, Yuhai Yang ${ }^{3}$, Haijun Liu ${ }^{1,2}$, Haijun Yang ${ }^{1,2,4}$, Yang Zhao ${ }^{1,2}$ \\ ${ }^{1}$ College of Biology and Geography Sciences, Yili Normal University, Yining City, Yili Kazak Autonomous Prefecture, China \\ 2 Institute of Resources and Ecology, Yili Normal University, Yining City, Yili Kazak Autonomous Prefecture, China \\ ${ }^{3}$ State Key Laboratory of Desert and Oasis Ecology, Xinjiang Institute of Ecology and Geography, Chinese Academy of Sciences, Urumqi, China \\ 4 Ministry of Education Key Laboratory of Vegetation Ecology, Institute of Grassland Science, Northeast Normal University, Changchun, China \\ Corresponding Author: Dong Cui \\ Email address: cuidongw@126.com
}

Background. Sophora alopecuroides L. (S. alopecuroides L.) is a perennial herb widely distributed throughout Xinjiang, China. It is characterized by its rapid diffusion ability.

Methods. To reveal the ecological mechanism of the rapid spread of $S$. alopecuroides, and to elucidate the ecological stoichiometric characteristics of $\mathrm{C}, \mathrm{N}$, and $\mathrm{P}$ (and the influencing factors) in the leaves of $S$. alopecuroides, leaves were sampled from four habitats-forest, roadside, farmland, and desert-across the Yili River Valley. The variation rules of the ecological stoichiometric characteristics of $\mathrm{C}, \mathrm{N}$, and P in the leaves of $S$. alopecuroides were analyzed. Correlations between the ecological stoichiometric characteristics of leaves and environmental factors were examined using redundancy analysis (RDA).

Results. (1) The C, N, and P contents of S. alopecuroides leaves were 391.30-533.10 g/kg, 8.90-43.14 $\mathrm{g} / \mathrm{kg}$, and 0.71-2.04 g/kg, respectively, and the C/N, C/P, and N/P ratios were 10.34-4.94, 209.05-698.73, and 10.78-31.43 respectively. (2) The $C$ content and C/P ratio of $S$. alopecuroides leaves were the highest in the desert habitat, leaf $\mathrm{N}$ content and $\mathrm{N} / \mathrm{P}$ ratio were the highest in the forest habitat, leaf $\mathrm{P}$ content was the highest in the farmland habitat, and the leaf $\mathrm{C} / \mathrm{N}$ ratio was the highest in the roadside habitat. (3) RDA showed that available potassium $(A K)$ and $\mathrm{pH}$ were the main factors affecting the ecological stoichiometric characteristics of $S$. alopecuroides leaves in Yili Valley $(p \leq 0.05)$, and these factors were positively correlated with $\mathrm{C}, \mathrm{N}, \mathrm{P}$, and N/P, and negatively correlated with $\mathrm{C} / \mathrm{P}$ and $\mathrm{C} / \mathrm{N}$. AK was the dominant factor that affected the $\mathrm{P}$ content of $\mathrm{S}$. alopecuroides leaves, and appropriate reduction of $\mathrm{K}$ fertilizer would be conducive to restraining the spread of S. alopecuroides. Soil C, N, P, and K content, soil organic matter $(\mathrm{OM})$, nitrate nitrogen $\left(\mathrm{NO}_{3}{ }^{-} \mathrm{N}\right)$, ammonium nitrogen $\left(\mathrm{NH}_{4}{ }^{+}-\mathrm{N}\right)$, and $\mathrm{AK}$ had no significant effect on the ecological stoichiometric characteristics of leaves $(p>0.05)$. 
1 Ecological stoichiometric characteristics and influencing

2 factors of carbon, nitrogen, and phosphorus in the leaves of

3 Sophora alopecuroides L. in the Yili River Valley, Xinjiang

4

5

6

7

8

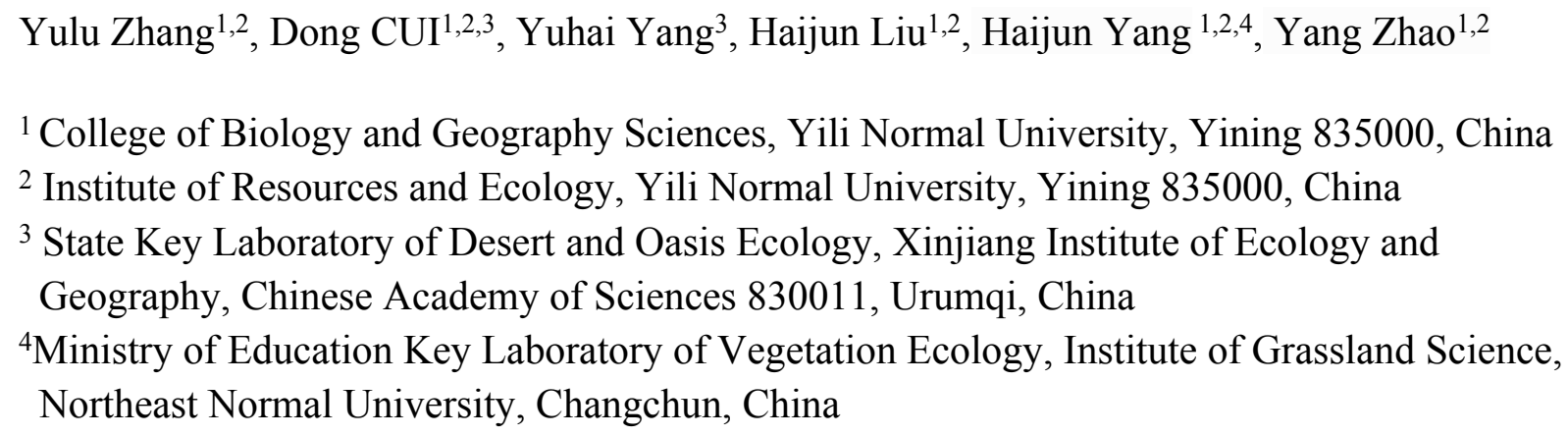

\begin{abstract}
Background. Sophora alopecuroides L. (S. alopecuroides L.) is a perennial herb widely distributed throughout Xinjiang, China. It is characterized by its rapid diffusion ability.

Methods. To reveal the ecological mechanism of the rapid spread of $S$. alopecuroides, and to elucidate the ecological stoichiometric characteristics of $\mathrm{C}, \mathrm{N}$, and $\mathrm{P}$ (and the influencing factors) in the leaves of $S$. alopecuroides, leaves were sampled from four habitats-forest, roadside, farmland, and desert - across the Yili River Valley. The variation rules of the ecological stoichiometric characteristics of $\mathrm{C}, \mathrm{N}$, and $\mathrm{P}$ in the leaves of $S$. alopecuroides were analyzed. Correlations between the ecological stoichiometric characteristics of leaves and environmental factors were examined using redundancy analysis (RDA).

Results. (1) The C, N, and P contents of S. alopecuroides leaves were $391.30-533.10 \mathrm{~g} / \mathrm{kg}$, $8.90-43.14 \mathrm{~g} / \mathrm{kg}$, and $0.71-2.04 \mathrm{~g} / \mathrm{kg}$, respectively, and the $\mathrm{C} / \mathrm{N}, \mathrm{C} / \mathrm{P}$, and N/P ratios were 10.344.94, 209.05-698.73, and 10.78-31.43 respectively. (2) The C content and C/P ratio of $S$. alopecuroides leaves were the highest in the desert habitat, leaf $\mathrm{N}$ content and N/P ratio were the highest in the forest habitat, leaf P content was the highest in the farmland habitat, and the leaf $\mathrm{C} / \mathrm{N}$ ratio was the highest in the roadside habitat. (3) RDA showed that available potassium (AK) and $\mathrm{pH}$ were the main factors affecting the ecological stoichiometric characteristics of $S$. alopecuroides leaves in Yili Valley $(p \leq 0.05)$, and these factors were positively correlated with $\mathrm{C}, \mathrm{N}, \mathrm{P}$, and $\mathrm{N} / \mathrm{P}$, and negatively correlated with $\mathrm{C} / \mathrm{P}$ and $\mathrm{C} / \mathrm{N}$. AK was the dominant factor that
\end{abstract}


40

41

42

43

44

45

46

47

48

49

50

51

52

53

54

55

56

57

58

59

60

61

62

63

64

65

66

67

68

69

70

71

72

73

74

75

76

77

78

affected the $\mathrm{P}$ content of $S$. alopecuroides leaves, and appropriate reduction of $\mathrm{K}$ fertilizer would be conducive to restraining the spread of $S$. alopecuroides. Soil $\mathrm{C}, \mathrm{N}, \mathrm{P}$, and $\mathrm{K}$ content, soil organic matter $(\mathrm{OM})$, nitrate nitrogen $\left(\mathrm{NO}_{3}{ }^{-}-\mathrm{N}\right)$, ammonium nitrogen $\left(\mathrm{NH}_{4}{ }^{+}-\mathrm{N}\right)$, and $\mathrm{AK}$ had no significant effect on the ecological stoichiometric characteristics of leaves $(p>0.05)$.

Keywords: S. alopecuroides L.; ecological stoichiometric characteristics; soil physicochemical factors; redundancy analysis.

\section{Introduction}

Ecological stoichiometry is a comprehensive science that studies the equilibrium relationships, quantitative relationships, and biogeochemical cycles of various chemical elements in ecological processes (Sterner \& Elser, 2002), providing an important technical means for analyzing the nutrient utilization of vegetation (Elser \& Schampel, 1996). The essence of plant growth is the regulation of the accumulation and relative proportions of $\mathrm{C}, \mathrm{N}$, and $\mathrm{P}$ in plants (Koerselman \& Meuleman, 1996). C, N, and P are essential nutrients for plant growth and development. $\mathrm{C}$ is the most important element in plant dry matter; $\mathrm{N}$ promotes the synthesis of amino acids and proteins, but also enhances the photosynthetic capacity of plants, and $\mathrm{P}$ is not only an important component of nucleic acids and enzymes, but also a basic element of all living organisms; thus, $\mathrm{C}, \mathrm{N}$, and $\mathrm{P}$ significantly affect plant growth and the regulation of physiological mechanisms (Wang et al., 2011).

Previous studies on the stoichiometric characteristics of $\mathrm{C}, \mathrm{N}$, and $\mathrm{P}$ have primarily focused on the stability of plant communities (Tessier \& Raynal, 2003), litter decomposition processes (Mooshammer et al., 2012), and determination of plant growth limiting elements (Tjoelker et al., 2005). The study of plant leaf ecological stoichiometry helps to explore plant growth characteristics and nutrient limitations. Leaves are the main sites of plant photosynthesis, and rate of photosynthesis are closely related to the $\mathrm{N}$ content of the leaves. The $\mathrm{C} / \mathrm{N}$ and $\mathrm{C} / \mathrm{P}$ ratios in leaves reflect the rate of plant carbon assimilation, and - to a certain extent — can reflect plant nutrient use efficiency (Wang \& Yu, 2008). Leaf N/P is a sensitivity index and an important evaluation tool for plant growth nutrient restriction (Duan et al., 2004). In addition, growth of plants has been found to be not only affected by $\mathrm{C}, \mathrm{N}$, and $\mathrm{P}$ levels in the plant tissues, but also by the external environment (Cleland, 2011). Soil moisture, salinity, and nutrients have a significant impact on the $\mathrm{C}, \mathrm{N}$, and $\mathrm{P}$ content of plant leaves and their stoichiometric ratios (Chen et al., 2016; Yan et al., 2011). The effective absorption of soil physical-chemical factors and soil nutrients will affect the ecological stoichiometric characteristics of plant leaves. Furthermore, the soil nutrient content and balance are closely related to the ecological stoichiometric characteristics. Soil nutrient levels not only affect plant growth and community composition but also indicate the health of the ecosystem (Li et al., 2014). Therefore, it is important to explore the characteristics of nutrient elements in the leaves and the physicochemical properties of the soil, which to understand nutrient utilization in plant growth and the adaptation mechanisms of plants to the environment. 
80

81

82

83

84

85

86

87

88

89

90

91

92

93

94

95

96

97

98

99

100

101

102

103

104

105

106

107

108

109

110

111

112

113

114

115

116

117

Sophora alopecuroides L. (S. alopecuroides L.) is a perennial herb of the legume family and is predominantly distributed in arid desert and grassland marginal areas, such as Xinjiang, Ningxia, and Inner Mongolia. It is characterized by salinity tolerance and drought resistance ( $Q i$ et al., 2008). Therefore, it is widely used in wind barriers, sand fixation, and saline-alkali land improvement (Chen \& Jia, 2000). Due to the fast-spreading characteristics of S. alopecuroides, populations often grow continuously and are distributed widely, which can form a single-species dominant community in a short time. In recent years, the grassland in the Yili River Valley of northwestern Xinjiang has been degenerating, in association with the spread of many poisonous weeds. Among them, $S$. alopecuroides has rapidly become the dominant species due to its rapid diffusion characteristics, occupying the living space of other species, and thus contributing to the degradation of the grasslands. The dominant presence of $S$. alopecuroides poses a serious threat to the development of local animal husbandry and biodiversity (Cui et al., 2018). Current research on $S$. alopecuroides mainly focuses on seed morphology, medicinal value, and seed dormancy and germination conditions (Liu et al., 2017; Hao et al., 2016; Wang et al., 2007). There are few reports addressing the ecological stoichiometric characteristics of $S$. alopecuroides leaves or their correlation with soil physicochemical factors.

The objective of this study was to reveal the survival strategies and ecological mechanisms leading to the rapid spread of $S$. alopecuroides in arid and semi-arid areas, and the effects of $S$. alopecuroides on soil quality in degraded steppes, to provide a theoretical basis for the scientific management and ecological restoration of degraded grasslands. Therefore, from the perspective of ecological stoichiometric characteristics, the present study examined $S$. alopecuroides leaves from the Yili River Valley, to systematically analyze the variation of the ecological stoichiometric characteristics of leaf-tissue $\mathrm{C}, \mathrm{N}$, and $\mathrm{P}$ levels across various habitats. Relationships were examined between environmental factors and the ecological stoichiometric characteristics of $S$. alopecuroides.

\section{Materials and Methods}

\section{Site description}

The study area was located in the Yili River Valley of the Xinjiang Uygur Autonomous Region $\left(80^{\circ} 09^{\prime}-84^{\circ} 56^{\prime} \mathrm{E}, 42^{\circ} 14^{\prime}-44^{\circ} 50^{\prime} \mathrm{N}\right)$. High mountains form the north, east, and south sides of the Yili River Valley. The terrain ranges from high in the east to low in the west, in the shape of a trumpet, so the natural landform can be described as "three mountains and two valleys," and is considered a "wet island." The elevation ranges from $530 \mathrm{~m}$ to $1,000 \mathrm{~m}$. The valley spans $360 \mathrm{~km}$ from east to west and $275 \mathrm{~km}$ from north to south, covering an area of $56,400 \mathrm{~km}^{2}$. The Yili River Valley is the wettest area in Xinjiang, with a warm and humid temperate continental climate. The average annual temperature is $10.4{ }^{\circ} \mathrm{C}$. Annual sunshine ranges between 2700 and $3000 \mathrm{~h}$, and the average annual precipitation is $417.6 \mathrm{~mm}$, of which approximately $60 \sim 70 \%$ occurs during the spring and summer. The Yili River Valley has 
118 abundant natural resources, high species diversity, various mineral deposits, and unique wetland

119

120

121

122

123

124

125

126

127

128

129

130

131

132

133

134

135

136

137

138

139

140

141

142

143

144

145

146

147

148

149

150

151

152

153

154

155

156

157

landscapes. Vegetation types in the valley are mainly grassland, meadow, and forest.

\section{Study site and sample collection}

Field investigation and observation revealed that $S$. alopecuroides, having strong invasion ability, often colonizes four landscapes — forest, roadside, farmland, and desert - in which it becomes widely distributed. Sampling sites were established in Qapqal County, Yili River Valley, covering those four habitat types (Figure 1). Soil samples were collected in September 2018, and plant samples were collected in July 2019.

In the four invasive habitats of $S$. alopecuroides, $20 \mathrm{~m} \times 20 \mathrm{~m}$ plots were selected respectively, and 3 quadrats were randomly selected from each plot, with an area of $5 \mathrm{~m} \times 5 \mathrm{~m}$. In each plot, 20 complete $S$. alopecuroides leaves were randomly selected, and taken back to the laboratory for cryopreservation. All collected leaves were dried at $70{ }^{\circ} \mathrm{C}$ for $24 \mathrm{~h}$. The leaves were then crushed into powder using a pulverizer, then sealed for storage. The contents of total C, total $\mathrm{N}$, and total $\mathrm{P}$ in the leaves of $S$. alopecuroides leaves were determined.

According to the same method, $20 \mathrm{~m} \times 20 \mathrm{~m}$ plots were set in four invasive habitats of $S$. alopecuroides, and three quadrats $(5 \mathrm{~m} \times 5 \mathrm{~m})$ were randomly set in each plot. Soil samples of $0 \sim 10 \mathrm{~cm}, 10 \sim 20 \mathrm{~cm}$, and 20 30 cm depth were collected from each quadrats. 36 soil samples were collected from the four habitats. The collected soil samples were placed in sealed plastic bags. After transportation to the laboratory, the soil samples were dried, ground with a mortar and pestle, then screened through a $0.5 \mathrm{~mm}$ mesh for soil physical-chemical properties o analyzed.

\section{Figure 1}

\section{Analysis of soil and plant properties Leaf properties of plants}

The total $\mathrm{C}$ content of the $S$. alopecuroides leaves was measured by a $\mathrm{K}_{2} \mathrm{CrO}_{7}-\mathrm{H}_{2} \mathrm{SO}_{4}$ oxidation procedure (Bao, 2000). For the total $\mathrm{N}$ content (TN) in the soil and plant samples, firstly, the soil and plant samples were boiled with perchloric acid $\left(\mathrm{HClO}_{4}\right)$ and sulfuric acid $\left(\mathrm{H}_{2} \mathrm{SO}_{4}\right)$, and then the total $\mathrm{N}$ content was determined by FOSS 1035 automatic nitrogen analyzer (Bao, 2000). To establish the total P content, firstly, the leaves and soil samples were boiled in perchloric acid and sulfuric acid, then the colorimetric method was applied using an Agilent CARY 60 ultraviolet-visible spectrophotometer; finally, the total phosphorus content (TP) of soil and plant samples was measured (Bao, 2000). The contents of $\mathrm{C}, \mathrm{N}$ and $\mathrm{P}$ were measured in $\mathrm{g} / \mathrm{kg}$.

\section{Soil physicochemical properties}

The total potassium $(\mathrm{K})$ content in the soil was measured using atomic absorption spectrophotometry $(\mathrm{Bao}, 2000)$. To determine the content of ammonium nitrogen $\left(\mathrm{NH}_{4}{ }^{+}-\mathrm{N}\right)$ and 
158

159

160

161

162

163

164

165

166

167

168

169

170

171

172

173

174

175

176

177

178

179

180

181

182

183

184

185

186

187

188

189

190

191

192

193

194

195

196

197

nitrate nitrogen $\left(\mathrm{NO}_{3}^{-}-\mathrm{N}\right)$ in the soil, firstly, $10.00 \mathrm{~g}$ of the soil sample was weighed into a plastic bottle, calcium chloride $\left(\mathrm{CaCl}_{2}\right)$ extractant was added, and the mixture was shaken for $30 \mathrm{~min}$ between $20^{\circ} \mathrm{C} \sim 25^{\circ} \mathrm{C}$, then measured the content of $\mathrm{NH}_{4}{ }^{+}-\mathrm{N}$ and $\mathrm{NO}_{3}{ }^{-}-\mathrm{N}$ by colorimetry after filtration $(\mathrm{Bao}, 2000)$. The content of soil organic matter $(\mathrm{OM})$ was measured by a $\mathrm{K}_{2} \mathrm{CrO}_{7^{-}}$ $\mathrm{H}_{2} \mathrm{SO}_{4}$ oxidation procedure $(\mathrm{Bao}, 2000)$. Soil $\mathrm{pH}$ was measured using a $\mathrm{pH}$ meter; To determine soil available phosphorus (AP), $2.50 \mathrm{~g}$ of each soil sample was weighed into a plastic bottle, then $\mathrm{NaHCO}_{3}$ extract and $1 \mathrm{~g}$ of phosphorus-free activated carbon was added; The sample was shaken for 30 min between $20^{\circ} \mathrm{C} \sim 25^{\circ} \mathrm{C}$, then filtered, and the content of AP in the soil sample was measured by colorimetry $(\mathrm{Bao}, 2000)$. The content of available potassium (AK) was determined by the flame photometric method (Bao, 2000).

\section{Statistical analysis}

Excel 2010 (Microsoft) and SPSS 19.0 statistics software were used to analyze the data after integration. One-way ANOVA method was used to analysis the differences in $\mathrm{C}, \mathrm{N}$, and $\mathrm{P}$ contents and their stoichiometric ratios in the leaves of S. alopecuroides across the four different habitats. And significance analysis was performed using Duncun multiple comparison. It should be noted that the factors significantly related to the ecological stoichiometric characteristics of $\mathrm{C}$, $\mathrm{N}$, and $\mathrm{P}$ need to be selected by Monte Carlo analysis before the redundancy analysis. According to the detrended correspondence analysis (DCA) of leaf $\mathrm{C}, \mathrm{N}$, and $\mathrm{P}$ contents, it can be seen that the length of gradient (LGA) of the sorting axis was less than 3, indicating the data had suitable linearity between the leaf nutrient levels and the soil environmental factors, which is suitable for the redundancy analysis (RDA).

In the sorting diagram, the quadrant in which the arrow is located represents a positive and negative correlation between the factors and the sorting axis, while the hollow arrow represents the ecological stoichiometric characteristics of the leaves. The solid arrow represents the physicochemical factors of the soil. The length of the line represents the relationship between the ecological stoichiometric characteristics of the leaves of $S$. alopecuroides and the soil chemical factors. The angle between the two arrows represents the correlation between the ecological stoichiometric characteristics of the leaves and soil chemical factors. The smaller the angle, the greater is the correlation. The solid line represents the environmental factors that were significantly related to the stoichiometric characteristics of the leaves $(p<0.05)$.

\section{Results}

\section{Content and stoichiometric ratios of $\mathrm{C}, \mathrm{N}$, and $\mathrm{P}$ in $\mathrm{S}$. alopecuroides leaves}

As indicated by Table 1, the average values of $\mathrm{C}, \mathrm{N}$, and $\mathrm{P}$ contents in the leaves of $S$. alopecuroides in the Yili River Valley were $470.09 \mathrm{~g} / \mathrm{kg}, 32.71 \mathrm{~g} / \mathrm{kg}$, and $1.43 \mathrm{~g} / \mathrm{kg}$, respectively. The coefficients of variation of $\mathrm{C}, \mathrm{N}$, and $\mathrm{P}$ were $10.96 \%, 30.41 \%$, and $30.86 \%$, respectively. The average values of $\mathrm{C} / \mathrm{N}, \mathrm{C} / \mathrm{P}$, and N/P were $16.88,364.67$, and 23.20 , respectively, and the variation coefficients were $57.04 \%, 38.42 \%$, and $24.00 \%$, respectively. The coefficients of 
198

199

200

201

202

203

204

205

206

207

208

209

210

211

212

213

214

215

216

217

218

219

220

221

222

223

224

225

226

227

228

229

230

231

232

233

234

235

236

237

variation of $\mathrm{C}, \mathrm{N}, \mathrm{P}$, and the stoichiometric ratios of leaves were generally large, with the largest being the coefficient of variation of the $\mathrm{C} / \mathrm{N}$ ratio, indicating that the $\mathrm{C}$ and $\mathrm{N}$ contents of the leaves had the highest degree of variation and the strongest variability. As shown in Figure $2 \mathrm{~A}$ and $2 \mathrm{~B}$, there was no significant correlation between leaf $\mathrm{C}$ content and leaf $\mathrm{N}$ and $\mathrm{P}$ content $(p>$ $0.05)$, while there is a strong positive correlation $(p<0.01)$ between leaf $\mathrm{N}$ and $\mathrm{P}$ contents (Figure 2C).The regression equation $\left(y=0.0009 x^{2}-0.0095 x+0.7532\right)$ clearly reflects the increasing trend of $\mathrm{P}$ content in leaves with increasing $\mathrm{N}$ content.

\section{Table 1}

Figure 2

\section{Contents and stoichiometric ratios of $\mathrm{C}, \mathrm{N}$, and $\mathrm{P}$ in $S$. alopecuroides leaves in different habitats}

There were some differences in the $\mathrm{C}$ and $\mathrm{P}$ contents of $S$. alopecuroides leaves in different habitats (Table 2). The $\mathrm{C}$ content of leaves in the habitats showed an increasing trend: the $\mathrm{C}$ content of leaves from the desert habitat was much higher than those from the forest. The coefficients of variation of $\mathrm{C}$ content in the leaves were $11.58 \%, 13.28 \%, 14.93 \%$, and $5.73 \%$ for the forest, roadside, farmland, and desert habitats, respectively. There was no significant difference in $\mathrm{N}$ content among the four habitats. The variation coefficients of $\mathrm{N}$ content in the forest, roadside, farmland, and desert habitats were $7.52 \%, 63.30 \%, 3.37 \%$, and $31.24 \%$, respectively. The $\mathrm{P}$ content of the leaves sampled from the four habitats in order from highest to lowest was farmland $>$ forest $>$ roadside $>$ desert, and the $\mathrm{P}$ content of the leaves from the desert was significantly lower than that of the farmland. The variation coefficients of $\mathrm{P}$ content in the leaves of the forest, roadside, farmland, and desert were $13.62 \%, 40.12 \%, 6.96 \%$, and $44.23 \%$, respectively.

There was a significant difference in the stoichiometric ratio of $\mathrm{C} / \mathrm{P}$ in the leaves of different habitats, but there were no significant differences in $\mathrm{C} / \mathrm{N}$ and N/P (Table 3 ). The $\mathrm{C} / \mathrm{N}$ ratio of the forest leaves was slightly lower than those of the desert, roadside, and farmland areas. The coefficients of variation of $\mathrm{C} / \mathrm{N}$ in the forest, roadside, farmland, and desert were 7.59 $\%, 75.31 \%, 12.19 \%$, and $22.65 \%$, respectively. The N/P ratio of leaves from the farmland habitat was less than that of the forest, roadside, and desert areas. The coefficients of variation of $\mathrm{N} / \mathrm{P}$ in the forest, roadside, farmland, and desert habitats were $13.31 \%, 41.23 \%, 5.09 \%$, and $19.31 \%$, respectively. The leaf $\mathrm{C} / \mathrm{P}$ of the four habitats, from largest to smallest, was desert $>$ roadside $>$ forest $>$ farmland, and the leaf $\mathrm{C} / \mathrm{P}$ of the farmland habitat was significantly lower than that of the desert. The coefficients of variation of $\mathrm{C} / \mathrm{P}$ in the forest, roadside, farmland, and desert habitats were $8.69 \%, 32.98 \%, 14.29 \%$, and $38.67 \%$, respectively.

\section{Table 2}

Peer] reviewing PDF | (2020:08:51868:6:0:NEW 13 May 2021) 
Correlation between ecological stoichiometric characteristics of $\boldsymbol{S}$. alopecuroides leaves and soil physicochemical factors

RDA was used to study the correlation between the ecological stoichiometric characteristics of $S$. alopecuroides leaves and the soil physicochemical factors $\left(\mathrm{AK}, \mathrm{pH}, \mathrm{NO}_{3}^{-}-\mathrm{N}^{-} \mathrm{NH}_{4}{ }^{+}-\mathrm{N}, \mathrm{AP}\right.$, $\mathrm{OM}$, soil $\mathrm{C}$ content, soil $\mathrm{N}$ content, soil $\mathrm{P}$ content, and soil $\mathrm{K}$ content). It can be seen from Table 4 that the interpretation amounts of the first and second sorting axes were $54.8 \%$ and $26.9 \%$, respectively. The first two axes jointly explained $81.7 \%$ of the change in the leaf ecological stoichiometric characteristics. The cumulative explanations of the leaf ecological stoichiometric

250

251

252

253

254

255

256

257

258

259

260

261

262

263

264

265

266

267

268

269

270

271

272

273

274

275

276

277 characteristics and soil physicochemical factors of $S$. alopecuroides leaves reached $86.8 \%$, indicating that the first two axes could reflect the large difference between the soil physicochemical factors and the leaf stoichiometric characteristics, and were mainly determined by the first sorting axis.

According to the RDA (Figure 3), the arrow line between AK and $\mathrm{pH}$ was the longest, which is consistent with the importance ranking results in Table 5. Together, AK and $\mathrm{pH}$ had the greatest impact on the ecological stoichiometric characteristics of $S$. alopecuroides leaves. AP and $\mathrm{pH}$ were positively correlated with leaf $\mathrm{C}, \mathrm{N}, \mathrm{P}$, and $\mathrm{N} / \mathrm{P}$, and negatively correlated with leaf $\mathrm{C} / \mathrm{P}$ and $\mathrm{C} / \mathrm{N}$. The direction of the arrow line of $\mathrm{AK}$ and leaf $\mathrm{P}$ content was almost the same with a small angle, indicating that AK was significantly positively related to leaf $\mathrm{P}$ content, and AK may be an important factor affecting leaf $\mathrm{P}$ content in $S$. alopecuroides leaves in the Yili River Valley.

Different soil physicochemical factors were found to exhibit significant differences in the ecological stoichiometric characteristics of $S$. alopecuroides leaves (Table 5). The effects of soil physicochemical factors on stoichiometric characteristics were as follows: $\mathrm{AK}>\mathrm{pH}>\mathrm{NO}_{3}{ }^{-}-\mathrm{N}>$ soil $\mathrm{P}$ content $>\mathrm{NH}_{4}{ }^{+}-\mathrm{N}>$ soil $\mathrm{N}$ content $>$ soil $\mathrm{K}$ content $>$ soil $\mathrm{OM}>$ soil $\mathrm{C}$ content $>\mathrm{AP}$. AK and $\mathrm{pH}$ had a significant effect on the stoichiometric characteristics of the leaves $(p \leq 0.05)$.

AK had the most significant effect on the stoichiometric characteristics of leaves, accounting for $19.9 \%$ of the total interpretation (4.487, $p=0.05) . \mathrm{NO}_{3}^{-}-\mathrm{N}$, soil $\mathrm{P}$ content, $\mathrm{NH}_{4}{ }^{+}-\mathrm{N}$, soil $\mathrm{N}$ content, soil $\mathrm{K}$ content, $\mathrm{OM}$, soil $\mathrm{C}$ content, and AP had no significant effect on the stoichiometric characteristics of the leaves $(p>0.05)$.

Table 4

Table 5

Figure 3 


\section{Discussion}

279 Ecological stoichiometric characteristics of $\mathbf{C}, \mathbf{N}$, and $\mathbf{P}$ in the leaves of $\boldsymbol{S}$. alopecuroides in 280 different habitats

281 The average C content (470.09 $\mathrm{mg} / \mathrm{g}$ ) of $S$. alopecuroides leaves in the Yili Valley was

282

283

284

285

286

287

288

289

290

291

292

293

294

295

296

297

298

299

300

301

302

303

304

305

306

307

308

309

310

311

312

313

314

315

316

317 slightly higher than the average of 492 global terrestrial plants leaves (464 mg/g; Elser et al., $2000 a$ ), indicating that the organic C content of $S$. alopecuroides in the Yili River valley was higher, therefore the ability to store $\mathrm{C}$ storage was stronger. There was a certain difference in leaf $\mathrm{C}$ content among the four habitats, which indicated that leaf carbon accumulation of $S$. alopecuroides in the four habitats was different.

The higher $\mathrm{C}$ content from the desert leaves may be because carbon usually exists in plants in the form of OM. Under conditions of low soil moisture and high salt content, a habitat will likely be high in stress and low in competitive interference. $S$. alopecuroides readily stores carbon, reduces its reproductive and competitive ability, maintains normal growth, and achieves balanced resource allocation (Zhang, 2000). It may also be the case that in an environment with sufficient resources, it is easy to reach environmental capacity saturation, which would aggravate interspecific competition and reduces the available natural resources.

Yili Valley lies within the arid and semi-arid region of Xinjiang. The average $\mathrm{N}$ content in the leaves of $S$. alopecuroides $(32.71 \mathrm{mg} / \mathrm{g})$ is not only much higher than the average of Chinese plant leaves (20.2 mg/g; Han et al., 2005), but also higher than average $\mathrm{N}$ content in plant leaves at a global scale $(20.6 \mathrm{mg} / \mathrm{g}$; Elser et al., 2000a). This seems consistent with previous observations that the $\mathrm{N}$ content of leaves from arid desert environments was relatively high ( $\mathrm{Li}$ et al., 2010); however, the N content in S. alopecuroides leaves showed no significant difference across the four habitats. $S$. alopecuroides is a leguminous plant with strong nodulation, and therefore nitrogen-fixation ability; this would explain the high $\mathrm{N}$ content in the leaves, as well as the high internal stability of $\mathrm{N}$ levels.

The average content of $\mathrm{P}$ in the leaves of $S$. alopecuroides $(1.43 \mathrm{mg} / \mathrm{g})$ was lower than the average of plants in China $(1.5 \mathrm{mg} / \mathrm{g}$; Han et al., 2005) and of that of global plants $(1.99 \mathrm{mg} / \mathrm{g}$; Elser et al., 2000a). The abundant precipitation of the Yili River Valley's temperate continental climate enhances the leaching of available $\mathrm{P}$ in the soil-which is not conducive to binding and accumulating $\mathrm{P}$-resulting in less $\mathrm{P}$ absorption by plant leaves (Wang et al., 2018). Previous studies have shown that human disturbance, such as the application of fertilizer, affects the plant chemometrics. Cultivation, fertilization, irrigation, and other activities improve the local soil's nutrient content and quality and improve the effective P content (Luo \& Gong, 2016), which would provide a favorable environment for $S$. alopecuroides growth. This explains the higher $\mathrm{P}$ content in the $S$. alopecuroides leaves from the farmland habitat compared to the other habitats.

$\mathrm{C} / \mathrm{N}$ and $\mathrm{C} / \mathrm{P}$ represent the ability to assimilate $\mathrm{C}$ when plants absorb nutrient elements. To some extent, it can reflect the utilization efficiency of nutrient elements in plants, and the ratios are closely related to the growth rates of organisms (Davis et al., 2006). In this study, the $\mathrm{C} / \mathrm{N}$ ratio (16.88) of $S$. alopecuroides leaves was lower than the global plant average (22.5; Elser et $a l ., 2000 b)$, and C/P (364.67) was much higher in the S. alopecuroides leaves than the global

Peer) reviewing PDF | (2020:08:51868:6:0:NEW 13 May 2021) 
318 plant average (232; Elser et al., 2000b), indicating that the nutrient utilization efficiency of $S$. 319 alopecuroides $\mathrm{L}$. was low. As shown in Table 3, the $\mathrm{C} / \mathrm{N}$ and $\mathrm{C} / \mathrm{P}$ ratios of $S$. alopecuroides 320 leaves grown in the desert and roadside habitats were higher than those of the farmland and 321 forest habitats. This finding may be because, in an environment with sufficient nutrition, the

322

323

324

325

326

327

328

329

330

331

332

333

334

335

336

337

338

339

340

341

342

343

344

345

346

347

348

349

350

351

352

353

354

355

356

357 growth rate of plants is high, the synthesis of organic carbon is high, and the $\mathrm{C} / \mathrm{N}$ and $\mathrm{C} / \mathrm{P}$ ratios are low. In nutrient-deficient environments, plant growth is relatively slow, the utilization efficiency of nutrient elements is high, and the $\mathrm{C} / \mathrm{N}$ and $\mathrm{C} / \mathrm{P}$ ratios are high ( $\mathrm{Ng}$ et al., 2014).

The ratio of $\mathrm{N}$ to $\mathrm{P}$ in plant leaves reflects the dynamic balance between soil nutrient supply and plant nutrient demand; the N/P ratio can be used to determine the limiting growth factors of plant nutrients (Duan et al., 2004). Studies have shown that when leaf N/P $<14$, plant growth is mainly restricted by $\mathrm{N}$; when leaf $\mathrm{N} / \mathrm{P}>16$, plant growth is mainly restricted by $\mathrm{P}$; and when leaf NP is more than 14, but less than 16, plant growth is restricted by both $\mathrm{N}$ and $\mathrm{P}$ (Aerts \& Chapin, 2000). S. alopecuroides is a nitrogen-fixing plant species, so it is generally N-limited, due to its higher leaf $\mathrm{P}$ content (mean $=1.53 \mathrm{mg} / \mathrm{g}$ ), indicating that it may not be P-limited. Therefore, the rule-of-thumb for judging restrictive elements - that is, an N/P of 14 or 16-may not greatly apply to nitrogen-fixing plants. Further studies are needed to determine which nutrients limit plant growth.

\section{Factors affecting the ecological stoichiometric characteristics of $\mathrm{C}, \mathrm{N}$, and $\mathrm{P}$ in $S$. alopecuroides leaves}

Plants need to absorb nutrients from the soil to supplement the nutrients needed for the growth and development of leaves, so soil physicochemical factors have a greater impact on the $\mathrm{C}, \mathrm{N}$, and $\mathrm{P}$ ecological stoichiometric characteristics of S. alopecuroides leaves. According to the observed RDA ranking, $\mathrm{AK}$ and $\mathrm{pH}$ were the main factors affecting the $\mathrm{C}, \mathrm{N}$, and $\mathrm{P}$ stoichiometric characteristics. Soil $\mathrm{pH}$ can change soil nutrient content and distribution area, thus affecting plant growth and developmental processes (Zhan et al., 2013). In this study, $\mathrm{pH}$ was positively correlated with $\mathrm{C}, \mathrm{N}$, and $\mathrm{P}$ contents and $\mathrm{N} / \mathrm{P}$ in $S$. alopecuroides leaves and was negatively correlated with $\mathrm{C} / \mathrm{P}$ and $\mathrm{C} / \mathrm{N}$, indicating that $\mathrm{pH}$ is closely related to leaf growth, which is similar to the finding that $\mathrm{pH}$ affects the growth and development of plants by affecting the physical, chemical, and biological characteristics of soil (Xu et al., 2015). In this study, it was observed that with an increase in the content of $\mathrm{AK}$, the $\mathrm{C}, \mathrm{N}, \mathrm{P}$, the N/P ratio in the leaves also increased, but $\mathrm{C} / \mathrm{P}$ and $\mathrm{C} / \mathrm{N}$ decreased. The content of $\mathrm{P}$ in the leaves was positively correlated with the content of $\mathrm{AK}$, indicating that $\mathrm{AK}$ was the main factor affecting the content of $\mathrm{P}$ in the leaves. This may be because the absorption efficiency of soil nutrients to $S$. alopecuroides leaves is different in arid and semi-arid areas compared to other environments. The absorption efficiency of AK is higher in arid and semi-arid areas, which benefits the growth of $S$. alopecuroides leaves.

The internal stability of grassland ecosystems in the arid and semi-arid areas of Xinjiang was explored by analyzing the influence of soil physicochemical factors on the ecological 
358

359

360

361

362

363

364

365

366

367

368

369

370

371

372

373

374

375

376

377

378

379

380

381

382

383

384

385

386

387

388

389

390

391

392

393

394

395

stoichiometric characteristics of S. alopecuroides leaves. The RDA indicated that the stoichiometric characteristics of $\mathrm{C}, \mathrm{N}$, and $\mathrm{P}$ in the sampled $\mathrm{S}$. alopecuroides leaves were not significantly affected by the OM, nitrate nitrogen, ammonium nitrogen, AK, or the soil C, N, P, and $\mathrm{K}$ levels. However, the independent analysis of the effect of soil physicochemical factors on the stoichiometric characteristics showed some deficiencies. First, the effects of soil physicochemical factors on the $\mathrm{C}, \mathrm{N}$, and $\mathrm{P}$ ecological stoichiometric characteristics of $S$. alopecuroides leaves were not independent. Second, soil physicochemical factors had mutual influence and restrictions. Therefore, based on the independent analysis, it is necessary to further analyze the double or even multiple synergistic effects of soil physicochemical factors on the ecological stoichiometric characteristics of $\mathrm{C}, \mathrm{N}$, and $\mathrm{P}$ in $S$. alopecuroides leaves, to make the results more accurate (Li et al., 2019).

As the dominant species degrading grassland in the Yili River Valley, the growth, development, and distribution of S. alopecuroides seriously affects the ecosystem in the valley. Studying the relationships between the $\mathrm{C}, \mathrm{N}$, and $\mathrm{P}$ ecological stoichiometric characteristics of leaves and environmental factors is of great significance in revealing the ecological mechanisms of the successful diffusion of S. alopecuroides plants in the Yili River Valley.

\section{Conclusions}

(a) The contents of C, N, and P in the leaves of S. alopecuroides in Yili Valley were 391.30$533.10 \mathrm{~g} / \mathrm{kg}, 8.90-43.14 \mathrm{~g} / \mathrm{kg}$, and $0.71-2.04 \mathrm{~g} / \mathrm{kg}$, respectively. The $\mathrm{C} / \mathrm{N}, \mathrm{C} / \mathrm{P}$, and N/P ratios were 10.34-44.94, 209.05-698.73, and 10.78-31.43, respectively. Compared with the global and national plant leaf averages, the $\mathrm{C}$ and $\mathrm{N}$ contents of the S. alopecuroides leaves in the arid desert environment were higher.

(b) There were significant differences in $\mathrm{C}$ and $\mathrm{P}$ contents, and the $\mathrm{C} / \mathrm{P}$ ratios between $S$. alopecuroides leaves in different habitats, but there were no significant differences in the $\mathrm{C}$ and $\mathrm{N}$ content or the $\mathrm{C} / \mathrm{N}$ and $\mathrm{N} / \mathrm{P}$ ratios in leaves from different habitats. The order of leaf $\mathrm{P}$ content in the four habitats was farmland $>$ forest $>$ roadside $>$ desert, and the order of leaf $\mathrm{C} / \mathrm{P}$ was desert $>$ roadside $>$ forest $>$ farmland, indicating that reclamation of farmland could boost the content of AP and provide a favorable environment for the growth of $S$. alopecuroides.

(c) $\mathrm{AK}$ and $\mathrm{pH}$ were the main factors affecting the ecological stoichiometric characteristics of S. alopecuroides leaves in Yili Valley ( $p \leq 0.05$ ); they were positively correlated with $\mathrm{C}, \mathrm{N}$, and $\mathrm{P}$ contents and the N/P ratio, and negatively correlated with $\mathrm{C} / \mathrm{P}$ and $\mathrm{C} / \mathrm{N}$ ratios. $\mathrm{AK}$ is the dominant factor affecting the $\mathrm{P}$ content of S. alopecuroides leaves. Appropriate reduction of $\mathrm{K}$ fertilizer is conducive to restraining the spread of S. alopecuroides.

\section{Acknowledgements}


396

397

398

399

400

401

402

403

404

405

406

407

408

409

410

411

412

413

414

415

416

417

418

419

420

421

422

423

424

425

426

427

428

429

430

431

432

433

434

435

We thank Saisai Zhang, Xia Yang, and Xiao Liu for their help with field investigation and sample collection. This study was supported by the Opening Fund of the State Key Laboratory of Desert and Oasis Ecology (grant number: G2020-02-02) and the Tianshan Youth Program, a special talent program in the Xinjiang Uygur Autonomous Region (grant number: 2018Q076).

\section{References}

Aerts R, Chapin F S. 2000. The mineral nutrition of wild plants revisited: a re-evaluation of processes and patterns. Advances in Ecological Research 30: 1-67 DOI 10.1016/S0065-2504(08)60016-1.

Bao S. 2000. Soil Agrochemical Analysis. Beijing: China Agriculture Press.

Chen M, Jia S. 2000. Forage plants in China. Beijing: China Agriculture Press.

Chen Q, Liu D, Ma C, Wang Z. 2016. Relationship between productivity, nitrogen and phosphorus nutrition structure and environmental factors of reed population in typical wetland of Tianjin. Journal of Ecology and Rural Environment 32(1):60-67 DOI 10.11934/j.issn.1673-4831.2016.01.011.

Cleland EE. 2011. Nutrient co-limitation of primary producer communities. Ecology Letters 14(9):852-862 DOI 10.1111/j.1461-0248.2011.01651.x

Cui D, Chen Y, Li W, Zhu C. 2018. Change of C, N, P content and stoichiometric characteristics of Sophora alopecuroides in the Yili River Valley. Acta Ecologica Sinica 38(17):6163-6170 DOI 10.5846/stxb201707101240.

Davis S E, Childers D L, Noe G B. 2006. The contribution of leaching to the rapid release of nutrients and carbon in the early decay of wetland vegetation. Hydrobiologia 569(1): 87-97 DOI 10.1007/s10750-006-0124-1.

Duan X, Wang X, Ouyang Z, Miao H, Guo R. 2004. Analysis of biomass and influencing factors of wild reed community in Wuliangsu Sea. Chinese Journal of Plant Ecology 28(2):246-251 DOI 10.17521/cjpe.2004.0036.

Elser J J, O' Brien W J, Dobberfuhl DR, Dowling. 2000a. The evolution of ecosystem processes : Growth rate and elemental stoichiometry of a key herbivore in temperate and arctic habitats. Journal of Evolutionary Biology 13:845-853 DOI 10.1046/j.14209101.2000.00215.x

Elser J J, Schampel J H. 1996. Organism size, Life history, and N:P stoichiometry. Bioscience 46:674-684.

Elser J J, Sterner R W, Gorokhova E, Fagan W F, Markow T A, Cotner J B, Harrison J F, Hobbie SE, Odell G M, Weider L W. 2000b. Biological stoichiometry from genes to ecosystems. Ecology Letters, 33(6):540-550

Han W, Fang J, Guo D, Zhang Y. 2005. Leaf nitrogen and phosphorus stoichiometry across 753 terrestrial plant species in China. New Phytologist 168:377-385 DOI 10.1111/j.1469-8137.2005.01530.x. 
436

437

438

439

440

441

442

443

444

445

446

447

448

449

450

451

452

453

454

455

456

457

458

459

460

461

462

463

464

465

466

467

468

469

470

471

472

473

474

475

476

Hao W, Meng G, Jie H. 2016. Research progress of chemical constituents and pharmacological action of Sophora alopecuroides. Chinese pharmacy 27(13): 1848-1850.

Koerselman W, Meuleman A F M. 1996. The vegetation N:P ratio: A new tool to detect the nature of nutrient limitation. Journal of Applied Ecology 33(6):1441-1450.

Li C, Xu X, Sun Y, Qiu Y, Li S, Gao P, Zhong X, Yan J, Wang G. 2014. Chemometric characteristics of C, N, P in leaves and soil of Three Desert Plants under different habitats. Geography of arid area 37 (5):996-1004.

Li X F, Li L, Chang Y P, Xu Z L. 2019. Stoichiometric characteristics of leaf carbon and nitrogen and their relationship with soil physical and chemical factors in Picea xuelingensis forest. Arid Land Geography 42(3):599-605.

Li Y, Mao W, Zhao X, Zhang T. 2010. Study on the stoichiometric characteristics of nitrogen and phosphorus in plant leaves of typical desert and desertification areas in northern China. Environmental science 31 (8):1716-1725 DOI CNKI: SUN:HJKZ.0.2010-08-004.

Liu Y, Zhao Y, Cui D, Leng J, Dong F. 2017. Effects of cotyledon injury on early growth of Sophora alopecuroides seedlings. Acta Prataculturae Sinica 26(8):139-145 DOI 10.11686/cyxb2017052.

Luo Y, Gong L. 2016. Ecostoichiometric characteristics of Phragmites australis in different habitats in the southern margin of Tarim Basin. Chinese Journal of Ecology 35(3):684691 Doi 10.13292/j.1000-4890.201603.020

Mooshammer M, Wanek W, Schnecker J, Wild B, Leitner S, Hofhansl F, Blöchl A, Hämmerle I, Frank A H, Fuchslueger L, Keiblinger K M, Zechmeister-Boltenstern S, Richter A. 2012. Stoichiometric controls of nitrogen and phosphorus cycling in decomposing beech leaf ltter. Ecology 93(4):770-782.

Ng E L, Patti F A, Rose MT, Schefe C R, Wilkinson K, Cavagnaro T R. 2014. Functional stoichiometry of soil microbial communities after amendment with stabilised organic matter. Soil Biology and Biochemistry 76:170-178 DOI 10.1016/j.soilbio.2014.05.016.

Qi X, He S, Shi G. 2008. Research progress of Sophora alopecuroides . Gansu Animal Husbandry and Veterinary 38(6):36-38 DOI 10.3969/j.issn.1006-799X.2008.06.021.

Sterner R W, Elser J J. 2002. Ecological stoichiometry: the biology of elements from molecules to the biosphere. Princeton, N.J.: Princeton University Press DOI 10.1038/423225b.

Tessier J T, Raynal D J. 2003. Vernal nitrogen and phosphorus retention by forest understory vegetation and soil microbes. Plant and Soil 256 (2):443-453 DOI 10.1023/A:1026163313038.

Tjoelker M G, Craine J M, Wedin D, Reich P B, Tilman D. 2005. Linking leaf and root trait syndromes among 39 grassland and savannah species. New Phytologist 167(2):493-508.

Wang J, Wang Z, Chen Y, Zhang Y, Luo G. 2007. Study on Germination Characteristics of Sophora alopecuroides seeds. Agricultural Research in the Arid Areas 25(4):202-206 DOI 10.3321/j.issn:1000-7601.2007.04.039.

Wang L, Zhang J, Geng Y, Ge S, Sun W, Fan S. 2018. Ecostoichiometric characteristics and influencing factors of carbon, nitrogen and phosphorus in reed leaves in wowachi wetland. Wetland science, 16(3):417-423 DOI CNKI:SUN:KXSD.0.2018-03-019. 
477

478

479

480

481

482

483

484

485

486

487

488

489

490

491

492

493

494

495

496

497

498

499

500

501

502

503

504

505

506

507

508

509

510

511

512

513

514

515

516
Wang S, Yu G. 2008. Ecostoichiometric characteristics of carbon, nitrogen and phosphorus in ecosystem. Acta Ecologica Sinica 28(8):3937-3947 DOI 10.3321/j.issn:10000933.2008.08.054.

Wang W, Xu L, Zeng C, Tong C, Zhang L. 2011. Ecological stoichiometric characteristics of carbon, nitrogen and phosphorus in living-dop litter-soil of estuarine wetland plants. Acta Ecologica Sinica 31(23):7119-7124.

Xu K, Shi L, Wang Y, Li M, Sun F, Liu S, Xi Y. 2015. The effect of $\mathrm{pH}$ value on the growth and development of switchgrass seedlings in hydroponics. Acta Ecologica Sinica 35(23): 7690-7698 DOI 10.5846/stxb201405040877.

Yan K, Fu D, He F, Duan C. 2011. Nutrient stoichiometry of plant leaves under different soil phosphorus levels in the phosphorus-rich areas of the Dianchi Lake Basin. Chinese Journal of Plant Ecology 35(4):353-361 DOI 10.3724/SP.J.1258.2011.00353.

Zhan X, Yu G, He N. 2013. Effects of plant functional types, climate and soil nitrogen on leaf nitrogen along the north-south transect of eastern China. Journal of Resources and Ecology 4(2): 125-32 DOI 10.5814/j.issn.1674-764x.2013.02.004.

Zhang D. 2000. Theoretical ecology research. Beijing: China Higher Education Press.

\section{Figure legends}

\section{Figure 1}

Diagram of sampling points in Yili Valley

\section{Figure 2}

Correlation of contents of $\mathrm{C}, \mathrm{N}$, and $\mathrm{P}$ in leaves of $S$. alopecuroides

\section{Figure 3}

Redundancy analysis of the influence of soil physicochemical properties on the ecological stoichiometric characteristics of leaves

LC: (leaf C) carbon content of $S$. alopecuroides leaves; LN: (leaf N) nitrogen content of leaves; LP: (leaf P) phosphorus content of leaves; L(C/N): carbon-nitrogen ratio of leaves; L(N/P): nitrogen-phosphorus ratio of leaves; $\mathrm{L}(\mathrm{C} / \mathrm{P})$ : carbon-phosphorus ratio of leaves; $\mathrm{C}$ : soil carbon content; N: soil nitrogen content; P: soil phosphorus content; K: soil potassium content. 
Figure 1

Diagram of sampling points in Yili Valley
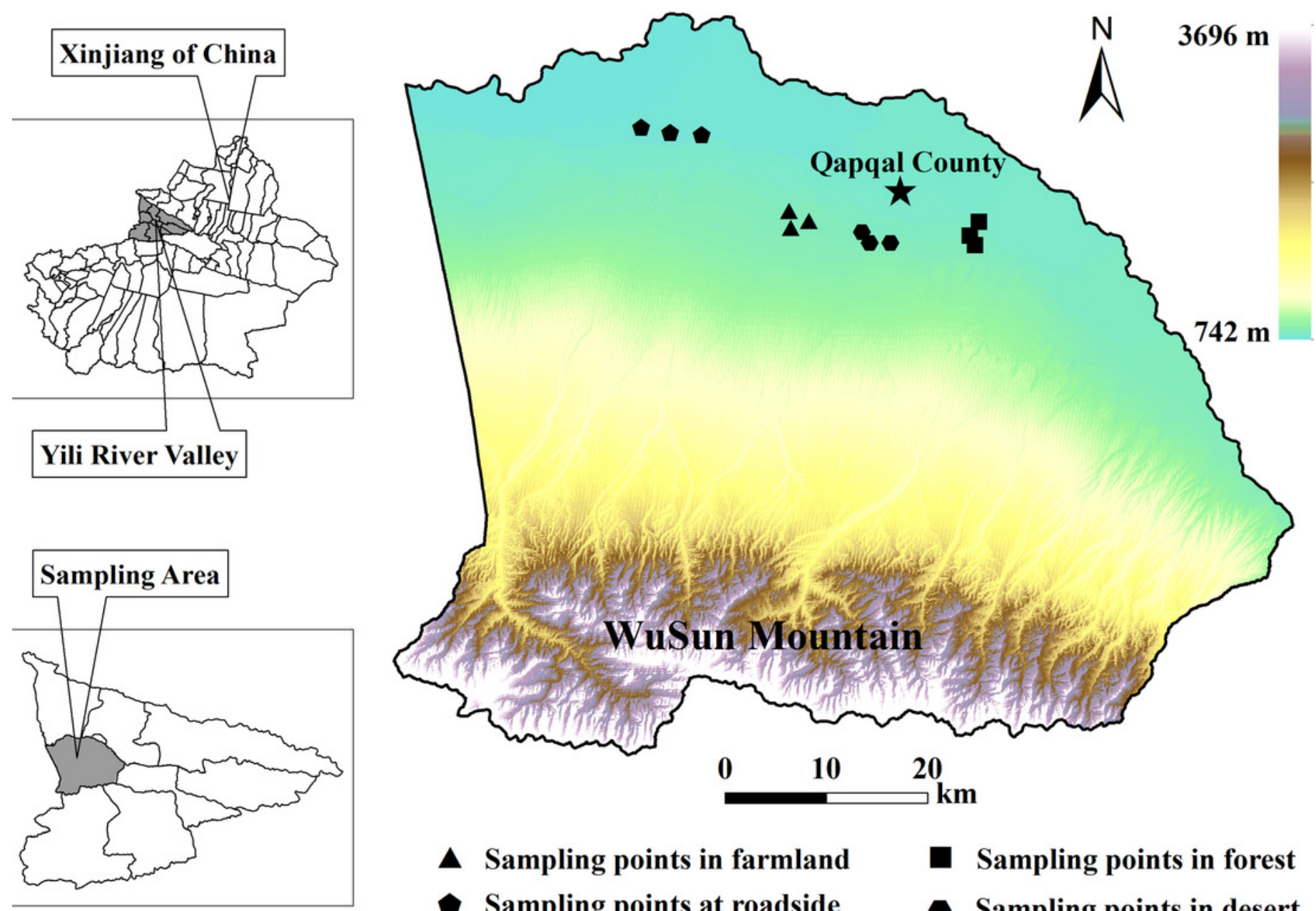

$\Delta$ Sampling points in farmland

- Sampling points at roadside
Sampling points in forest

- Sampling points in desert 
Figure 2

Correlation of contents of $\mathrm{C}, \mathrm{N}$, and $\mathrm{P}$ in leaves of $\mathrm{S}$. alopecuroides
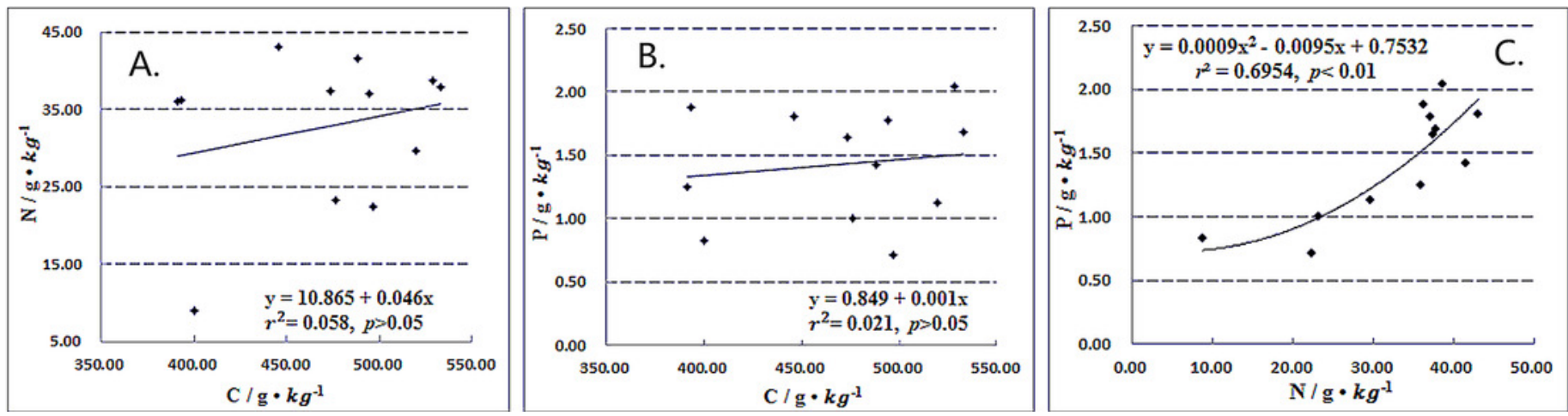
Figure 3

Redundancy analysis of the influence of soil physicochemical properties on the ecological stoichiometric characteristics of leaves

LC: (leaf C) carbon content of $S$. alopecuroides leaves; LN: (leaf N) nitrogen content of leaves;

LP: (leaf P) phosphorus content of leaves; $L(C / N)$ : carbon-nitrogen ratio of leaves; $L(N / P)$ :

nitrogen-phosphorus ratio of leaves; L(C/P): carbon-phosphorus ratio of leaves; C: soil carbon content; N: soil nitrogen content; P: soil phosphorus content; K: soil potassium content.

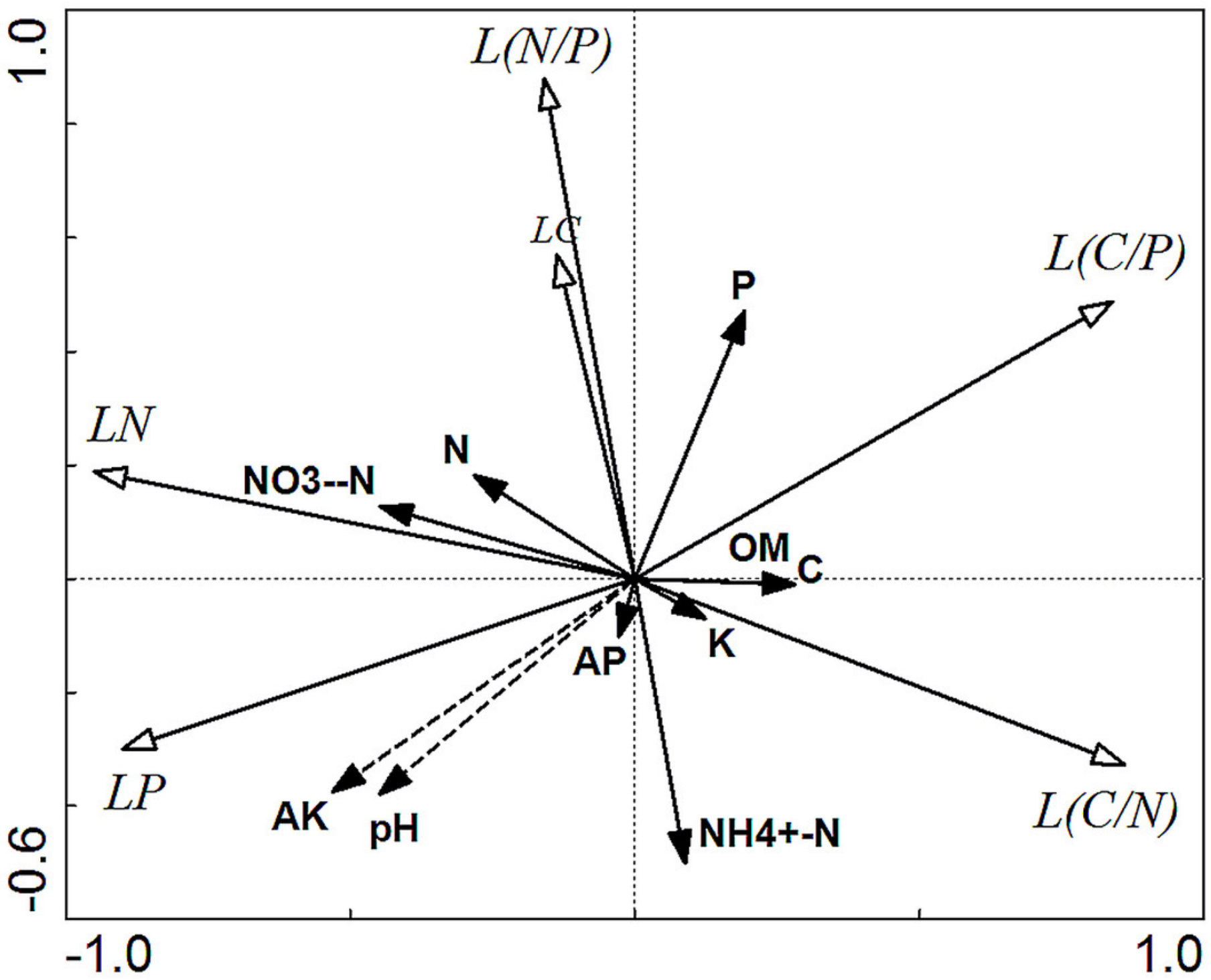




\section{Table 1 (on next page)}

Ecological stoichiometry characteristics of $\mathrm{C}, \mathrm{N}$ and $\mathrm{P}$ in the Sophora alopecuroides leaves. 
1 Table 1

2 Ecological stoichiometry characteristics of C, N and P in the Sophora alopecuroides leaves.

\begin{tabular}{ccccccc}
\hline & $\mathbf{C}(\mathbf{g} / \mathbf{k g})$ & $\mathbf{N}(\mathbf{g} / \mathbf{k g})$ & $\mathbf{P}(\mathbf{g} / \mathbf{k g})$ & $\mathbf{C} / \mathbf{N}$ & $\mathbf{C} / \mathbf{P}$ & $\mathbf{N} / \mathbf{P}$ \\
\hline Mean & 470.09 & 32.71 & 1.43 & 16.88 & 364.67 & 23.20 \\
Median & 482.26 & 36.70 & 1.53 & 13.48 & 314.75 & 23.06 \\
Standard & 14.87 & 2.87 & 0.13 & 2.78 & 40.44 & 1.61 \\
$\quad$ Error & & & & & & \\
Range & $391.30 \sim 533.10$ & $8.90 \sim 43.14$ & $0.71 \sim 2.04$ & $10.34 \sim 44.94$ & $209.05 \sim 698.73$ & $10.78 \sim 31.43$ \\
Coefficient of & 10.96 & 30.41 & 30.86 & 57.04 & 38.42 & 24.00 \\
Variation (\%) & & & & & & \\
\hline
\end{tabular}

3 


\section{Table 2 (on next page)}

Contents of $\mathrm{C}, \mathrm{N}$ and $\mathrm{P}$ in leaves of Sophora alopecuroides in different habitats and their variation coefficients.

The value is (mean $\pm S D$ ). Different letters in the upper right corner of the peer data indicate that the data in different habitats are significantly different $(p<0.05)$. 
1 Table 2

2 Contents of $\mathrm{C}, \mathrm{N}$ and $\mathrm{P}$ in leaves of Sophora alopecuroides in different habitats and their variation 3 coefficients.

\begin{tabular}{|c|c|c|c|c|}
\hline & Forest & Roadside & Farmland & Desert \\
\hline $\mathrm{C}(\mathrm{g} / \mathrm{kg})$ & $(450.98 \pm 52.21)^{b}$ & $(455.22 \pm 60.44)^{\mathrm{ab}}$ & $(472.05 \pm 70.47)^{\mathrm{ab}}$ & $\begin{array}{c}(502.09 \pm \\
28.76)^{\mathrm{a}}\end{array}$ \\
\hline $\begin{array}{l}\text { Coefficient of } \\
\text { Variation (\%) }\end{array}$ & 11.58 & 13.28 & 14.93 & 5.73 \\
\hline $\mathrm{N}(\mathrm{g} / \mathrm{kg})$ & $(38.35 \pm 2.88)^{\mathrm{a}}$ & $(27.25 \pm 17.25)^{\mathrm{a}}$ & $(37.39 \pm 1.26)^{\mathrm{a}}$ & $(27.83 \pm 8.69)^{\mathrm{a}}$ \\
\hline $\begin{array}{l}\text { Coefficient of } \\
\text { Variation (\%) }\end{array}$ & 7.52 & 63.30 & 3.37 & 31.24 \\
\hline $\mathrm{P}(\mathrm{g} / \mathrm{kg})$ & $(1.44 \pm 0.20)^{\mathrm{ab}}$ & $(1.25 \pm 0.50)^{\mathrm{ab}}$ & $(1.90 \pm 0.13)^{\mathrm{a}}$ & $(1.13 \pm 0.50)^{b}$ \\
\hline $\begin{array}{l}\text { Coefficient of } \\
\text { Variation (\%) }\end{array}$ & 13.62 & 40.12 & 6.96 & 44.23 \\
\hline
\end{tabular}

4 The value is (mean $\pm \mathrm{SD}$ ). Different letters in the upper right corner of the peer data indicate that the data in

5 different habitats are significantly different $(p<0.05)$.

6 


\section{Table 3(on next page)}

Ratios of carbon-nitrogen, carbon-phosphorus, nitrogen-phosphorus and coefficient of variation in leaves of Sophora alopecuroides in different habitats.

The value is (mean \pm SD). Different letters in the upper right corner of the peer data indicate that the data in different habitats are significantly different $(p<0.05)$. 
1 Table 3

2 Ratios of carbon-nitrogen, carbon-phosphorus, nitrogen-phosphorus and coefficient of variation in

3 leaves of Sophora alopecuroides in different habitats.

\begin{tabular}{ccccc}
\hline & Forest & Roadside & Farmland & Desert \\
\hline C/N & $(11.75 \pm 0.89)^{\mathrm{a}}$ & $(24.26 \pm 18.27)^{\mathrm{a}}$ & $(12.60 \pm 1.54)^{\mathrm{a}}$ & $(18.93 \pm 4.29)^{\mathrm{a}}$ \\
$\begin{array}{c}\text { Coefficient of } \\
\text { Variation (\%) }\end{array}$ & 7.59 & 75.31 & 12.19 & 22.65 \\
C/P & $(315.27 \pm 27.39)^{\mathrm{ab}}$ & $(397.90 \pm 131.21)^{\mathrm{ab}}$ & $(248.56 \pm 35.51)^{\mathrm{b}}$ & $(496.97 \pm 192.18)^{\mathrm{a}}$ \\
$\begin{array}{l}\text { Coefficient of } \\
\text { Variation (\%) }\end{array}$ & 8.69 & 32.98 & 14.29 & 38.67 \\
N/P & $(26.99 \pm 3.59)^{\mathrm{a}}$ & $(20.37 \pm 8.40)^{\mathrm{a}}$ & $(19.71 \pm 1.00)^{\mathrm{a}}$ & $(25.71 \pm 4.97)^{\mathrm{a}}$ \\
Coefficient of & 13.31 & 41.23 & 5.09 & 19.31 \\
Variation (\%) & & & & \\
\hline
\end{tabular}

4 The value is (mean $\pm \mathrm{SD}$ ). Different letters in the upper right corner of the peer data indicate that the data in

5 different habitats are significantly different $(p<0.05)$.

6 


\section{Table 4 (on next page)}

Correlation between ecological stoichiometry characteristics of leaves and sorting axis. 
1 Table 4

2 Correlation between ecological stoichiometry characteristics of leaves and sorting axis.

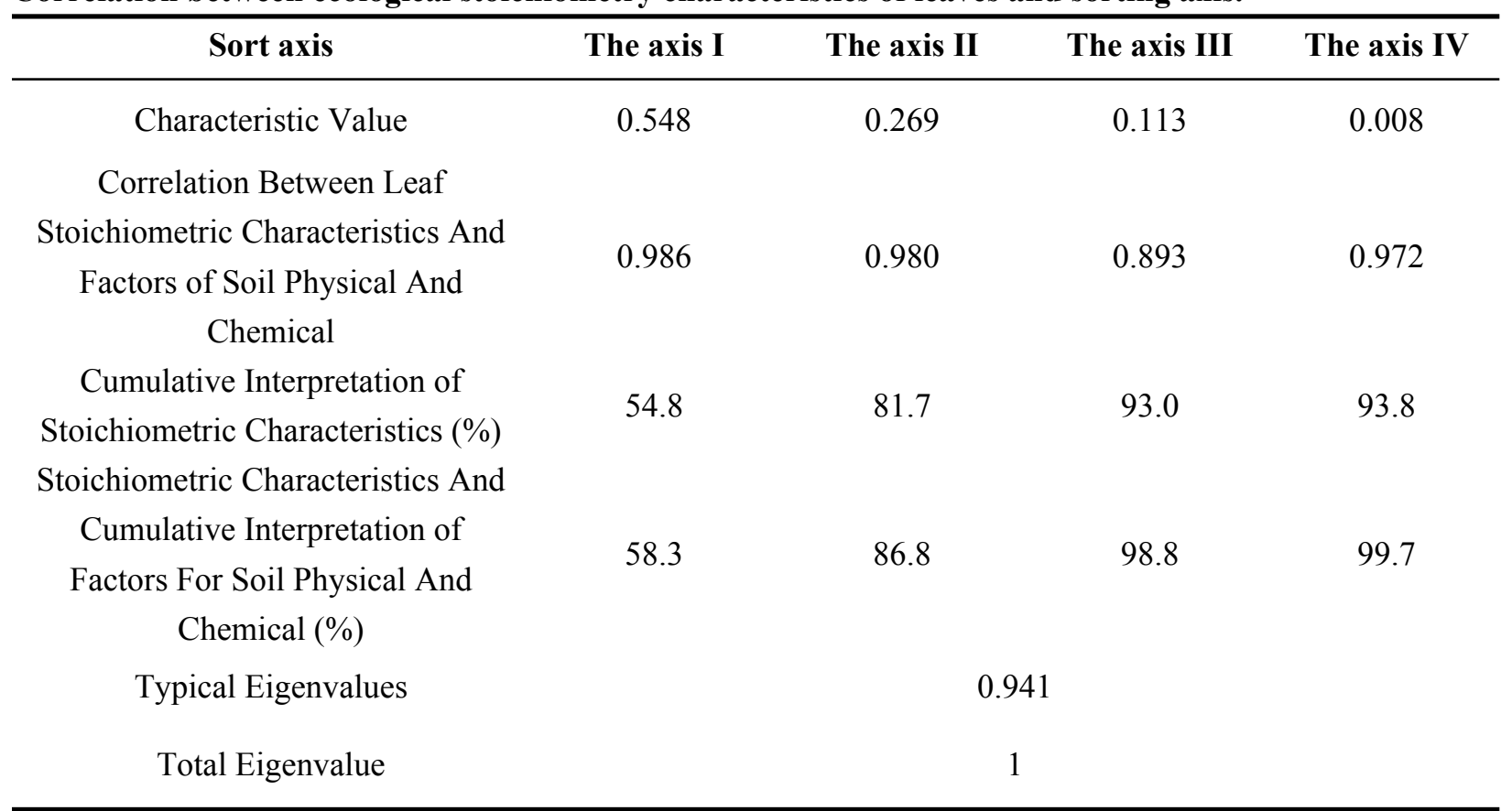

3 


\section{Table 5 (on next page)}

Significance rank and significance test of soil physicochemical factors in explanation. 
1 Table 5

2 Significance rank and significance test of soil physicochemical factors in explanation.

\begin{tabular}{ccccc}
\hline $\begin{array}{c}\text { Environmental } \\
\text { Factor }\end{array}$ & $\begin{array}{c}\text { Significance } \\
\text { Rank }\end{array}$ & $\begin{array}{c}\text { Explanatory Capacity } \\
(\%)\end{array}$ & $\begin{array}{c}\text { Importance } \\
(\boldsymbol{F} \text { Value })\end{array}$ & $\begin{array}{c}\text { Saliency } \\
(\boldsymbol{p} \text { Value })\end{array}$ \\
\hline $\mathrm{AK}$ & 1 & 19.9 & 4.487 & 0.042 \\
$\mathrm{pH}$ & 2 & 15.4 & 2.916 & 0.050 \\
$\mathrm{NO}_{3}-\mathrm{N}$ & 3 & 14.1 & 1.646 & 0.188 \\
Soil P Content & 4 & 8.6 & 0.939 & 0.418 \\
$\mathrm{NH} 4+-\mathrm{N}$ & 5 & 8.5 & 0.924 & 0.444 \\
Soil N Content & 6 & 5.8 & 0.620 & 0.628 \\
Soil K Content & 7 & 4.9 & 0.512 & 0.722 \\
OM & 8 & 4.6 & 0.480 & 0.72 \\
Soil C Content & 9 & 4.5 & 0.476 & 0.698 \\
AP & 10 & 0.7 & 0.073 & 0.982 \\
\hline
\end{tabular}

3 